\title{
Iron status in runners of various running specialities \\ BY
}

G. MOUTON $\left({ }^{1}\right)$, F. E. SLUSE $\left({ }^{2}\right)$, A. BERTRAND $\left({ }^{3}\right)$, A. WELTER $\left({ }^{3}\right)$, J. L. CABAY and G. CAMUS (*)

[( $\left.{ }^{(}\right)$Physician, track and field coach; $\left(^{(}\right)$Laboratoire de Bioénergétique, Université de Liège; $\left({ }^{3}\right)$ Laboratoire du Vieux Mayeur, Liège; (') Laboratoire de Physiologie Humaine Appliquée, Research Associate F.N.R.S., Université de Liège]

The blood iron status of 44 male runners of various running specialities (18 sprinters, 13 middle- and 13 long-distance runners) is evaluated by measuring serum ferritin (SF), serum iron (Si), hemoglobin concentration $(\mathrm{Hb})$, hematocrit $(\mathrm{Ht})$, red blood cells content $(\mathrm{RBC})$ and haptoglobin concentration $(\mathrm{Hp})$. The results of these analyses (except $\mathrm{Hp}$ ) are compared to those obtained in sedentary male subjects (control group) of the same mean age. Mean SF, SI, $\mathrm{Hb}$ and $\mathrm{Ht}$ measured in athletes are significantly lower than in control group. The remarkably low Hp values obtained in athletes suggests the occurrence of hemolysis. Using unpaired $t$ test, it appears that the blood iron status of these runners does not depend on their running speciality.

\section{Introduction}

Iron deficiency and suboptimal hemoglobin concentration have been reported among athletes, especially in distance runners involved in intense physical training (Dufaux et al., 1981). It has been suggested that this phenomenon is the result of increased hemolysis (Dufaux et al., 1981) and iron excretion through sweat (EHN et al., 1980) and urine (BLACKLOK, 1977) in combination with reduced absorption of iron from the gut (EHN et al., 1980). According to Duraux et al. (1981), distance runners have a greater need of iron than other athletes because of greater loss of iron through hemolysis. The hypothesis was made that this greater hemolysis in runners is due to mechanical destruction of red blood cells caused by repeated foot strikes on the ground (Dufaux et al., 1981).

The aim of this study is to compare the iron status of runners of various running specialities. We have measured serum iron, serum ferritin, haptoglobin and hemoglobin concentrations in the blood of long- and middle-distance runners. We have compared these results to those obtained in sprinters and in healthy but sedentary young men of the same age.

\section{Analytical procedures and Methods}

Venous blood samples were taken at rest in the supine position in 44 male runners divided in 3 groups according to their running speciality (group $1: 18$ sprinters, 
TABLE I. Mean red blood cell content (RBC) and haptoglobin concentration (Hp) in athletes and control group. The $\mathrm{Hp}$ value in controls is taken from Dufaux et al. (1981). The standard deviation and range are also indicated.

\begin{tabular}{l|c|c}
\hline & $\begin{array}{c}\mathrm{RBC} \\
\left(10^{6} / \mathrm{mm}^{3}\right)\end{array}$ & $\begin{array}{c}\mathrm{Hp} \\
(\mathrm{mg} / 100 \mathrm{ml})\end{array}$ \\
\hline Control $(n=32)$ & $\begin{array}{c}5.09 \pm 0.39 \\
(4.39 \text { to } 5.90)\end{array}$ & $\begin{array}{c}105 \pm 40^{*} \\
n=28\end{array}$ \\
Sprinters $(n=18)$ & $5.03 \pm 0.34$ & $45.7 \pm 18.0$ \\
& $(4.33$ to 5.72$)$ & $(17.4$ to 89.8$)$ \\
Middle-distance runners $(n=13)$ & $4.84 \pm 0.34$ & $39.7 \pm 19.2$ \\
& $(4.35$ to 5.54$)$ & $(8.0$ to 59.5$)$ \\
Long-distance runners $(n=13)$ & $4.88 \pm 0.34$ & $32.8 \pm 23.0$ \\
& $(4.26$ to 5.42$)$ & $(1.0$ to 65.4$)$ \\
\hline
\end{tabular}

* from Dufaux et al. (1981)

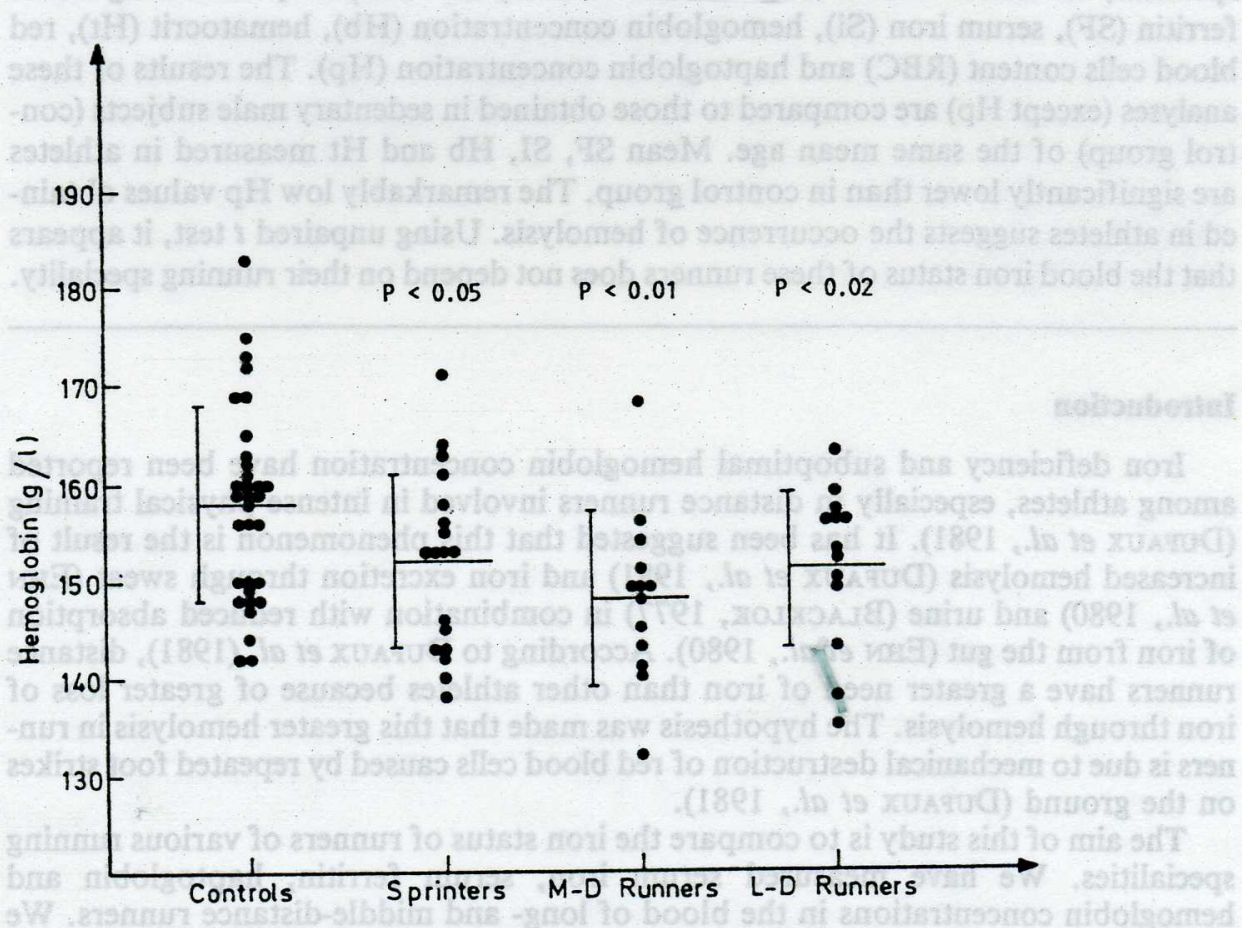

FIG 1. Hemoglobin concentration in controls and runners. The mean values are represented by horizontal bars and the vertical bars represent the standard deviation. Significance differences between athletes and controls are also given.

group $2: 13$ middle-distance runners, group $3: 13$ long-distance runners) and in 32 to 52 healthy male subjects (moderately physically active or sedentary) of the same 
mean age (control group, group 4). The subjects of groups 1, 2 and 3 participated regularly in athletic competitions and trained at least four times a week.

The iron status of the control subjects was established on the occasion of routine medical examination but the blood analysis of the runners were performed with the intention to determine the possible causes of their general state of fatigue. All these subjects were examined on their own request. Some of them complained about general state of fatigue and deterioration of athletic performances sometimes in association with muscular sensations of pain and inability to achieve their usual training programs.

Hemoglobin $(\mathrm{Hb})$ and red blood cells $(\mathrm{RBC})$ were measured using a Coulter Counter Model S TR3 (Coulter Electronics Ltd, U.K.). Hematocrit (Ht) was measured by microcentrifugation. Serum ferritin (SF) was assayed by radioimmunoassay (Leeco Diagnostics Inc. USA) (GoLDIE \& ThомAs, 1978). Serum iron (SI) was measured by the Ferrozine method using the Merz \& Dade Kit (Switzerland) (STOOKEY, 1970). The haptoglobin (Hp) content of blood was assessed by nephelometry (ICB BECKMAN Instruments Inc., USA). All tests were performed according to kits and apparatus manufacturers.

The results were compared on a statistical basis using the Student's unpaired $t$ test.

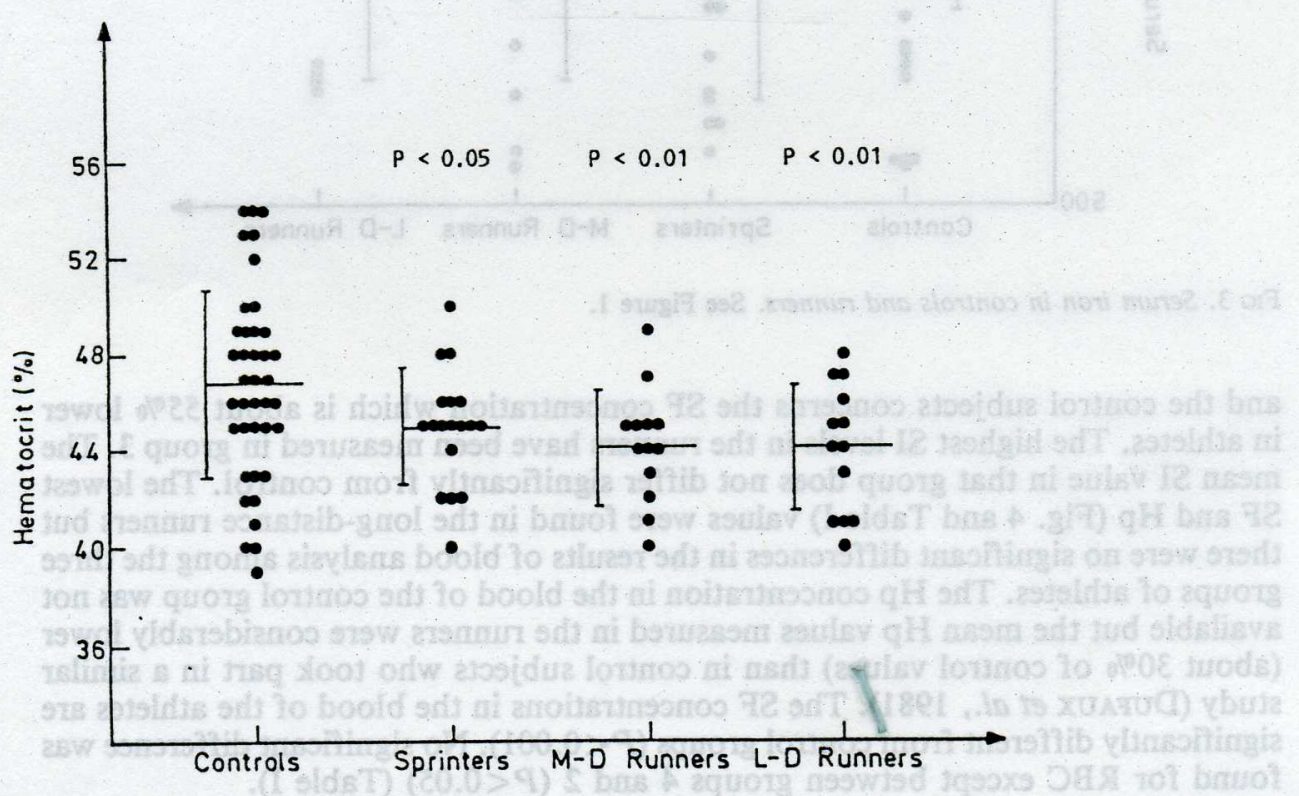

FIG 2. Hematocrit in controls and runners. See Figure 1.

\section{Results}

Part of the results of blood analysis performed in our subjects are presented in Table $I$ and in Figures 1 to 4 . Using unpaired $t$ test, it appears that the average hemoglobin concentration, hematocrit level, serum iron and serum ferritin for the three groups of runners are significantly lower $(P<0.05)$ than for the control subjects. While significantly lower than in the control group, mean $\mathrm{Hb}$ and $\mathrm{Ht}$ levels in runners are within the range usually considered as normal. The upward limit of the ranges are shifted to lower values. The most striking difference between the runners 


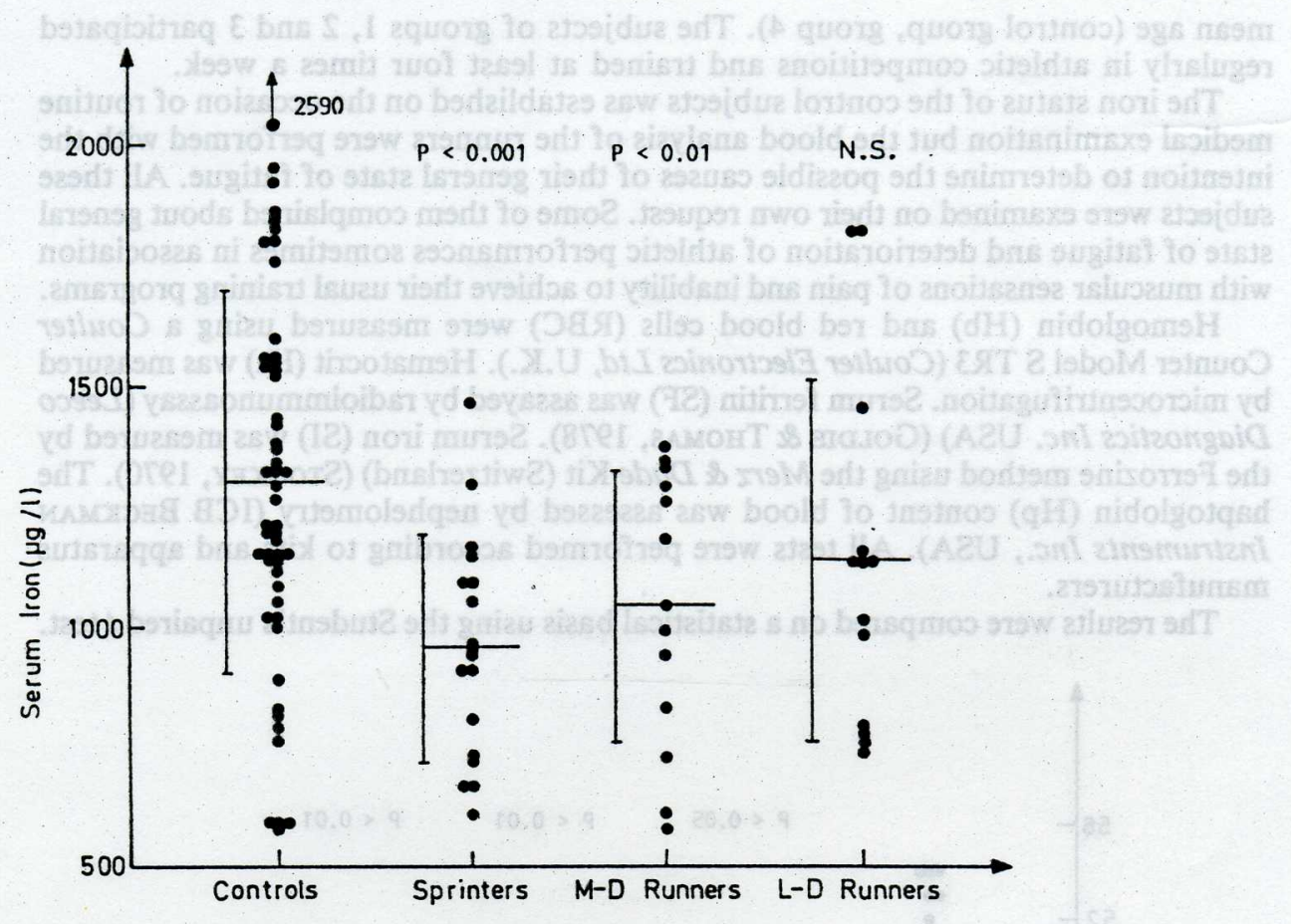

FIG 3. Serum iron in controls and runners. See Figure 1.

and the control subjects concerns the SF concentration which is about $55 \%$ lower in athletes. The highest SI levels in the runners have been measured in group 3. The mean SI value in that group does not differ significantly from control. The lowest $\mathrm{SF}$ and Hp (Fig. 4 and Table I) values were found in the long-distance runners but there were no significant differences in the results of blood analysis among the three groups of athletes. The Hp concentration in the blood of the control group was not available but the mean $\mathrm{Hp}$ values measured in the runners were considerably lower (about $30 \%$ of control values) than in control subjects who took part in a similar study (Dufaux et al., 1981). The SF concentrations in the blood of the athletes are significantly different from control groups $(P<0.001)$. No significant difference was found for RBC except between groups 4 and $2(P<0.05)$ (Table I).

\section{Discussion}

During the last few years a great deal of interest has focused on the iron status of athletes. Our results confirm known data on iron metabolism in athletes. Suboptimal $\mathrm{Hb}$ levels, low serum iron and ferritin concentrations have been reported (CLEMENT \& AsMundson, 1982). According to Pate (1983), the optimal $\mathrm{Ht}$ value for oxygen transport in athlete is equal to $45 \%$ and corresponds to a $\mathrm{Hb}$ concentration of $160 \mathrm{~g} /$ litre. As a consequence, any $\mathrm{Hb}$ concentration lower than 150 to $160 \mathrm{~g} /$ litre could be too low for endurance athletes and could be considered as suboptimal $\mathrm{Hb}$ concentration for athletes (PATE, 1983). 


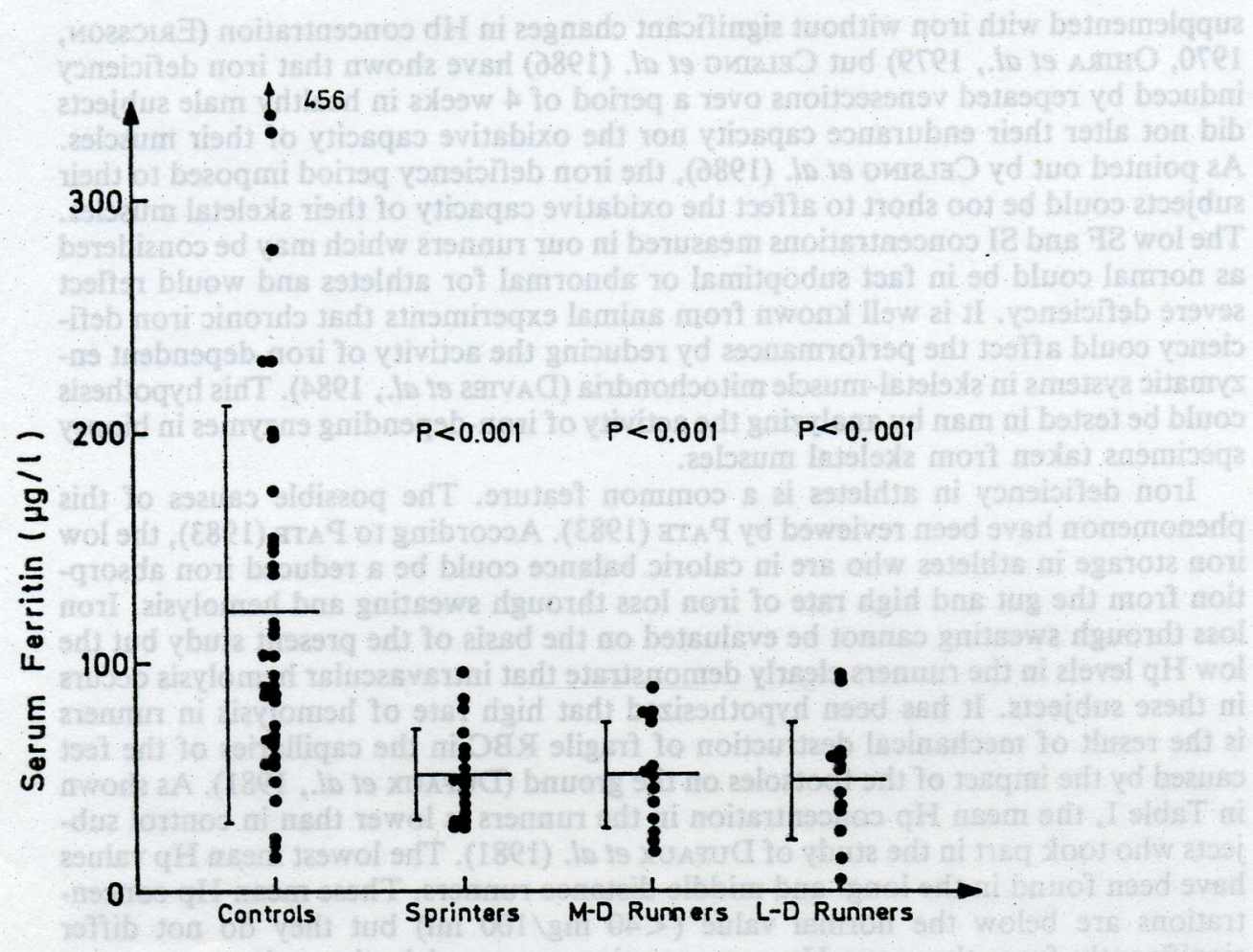

Fig 4. Serum ferritin in controls and runners. See Figure 1.

The results of the present study show that the mean $\mathrm{Ht}$ and $\mathrm{Hb}$ concentrations in atheletes are significantly lower than in sedentary subjects but the difference is quite small. However the mean values of $\mathrm{Hb}$ and $\mathrm{Ht}$ calculated by pooling the data in the three groups of runners may be considered as a lower limit for optimal levels. It is thus unlikely that the state of fatigue of these athletes and the degradation of their performances could be explained by a reduction of the oxygen-carrying capacity of their blood giving rise to a decrease of their maximum oxygen uptake. It must be noted, however, that $\mathrm{Hb}$ concentrations below $150 \mathrm{~g} /$ litre have been measured in 20 over 44 runners.

The data presented in Figures 3 and 4 clearly show that the SI and SF concentrations are significantly lower in the athletes' groups. This observation is in agreement with the results of previous study (Dufaux et al., 1981). The mean SF and SI concentrations measured in our athletes are close to that reported by CLEMENT \& ASMUNDsoN (1982) in 52 male endurance runners. It has been shown that the iron stores of the body are well correlated with SF concentration (LIPSCHITZ et al., 1974). As a consequence, it can be concluded that low SF levels reflect iron deficiency. From the results of the present investigation, it cannot be concluded directly that the diminished iron stores are involved in the reduction of performances of our athletes since the relationship between these two parameters was not studied. In any case, the effects of iron depletion without anemia on work capacity of human subjects are controversial. Some studies reported increased physical performances in humans 
supplemented with iron without significant changes in Hb concentration (ERICsson, 1970, OHIRA et al., 1979) but CELSING et al. (1986) have shown that iron deficiency induced by repeated venesections over a period of 4 weeks in healthy male subjects did not alter their endurance capacity nor the oxidative capacity of their muscles. As pointed out by CELSING et al. (1986), the iron deficiency period imposed to their subjects could be too short to affect the oxidative capacity of their skeletal muscles. The low SF and SI concentrations measured in our runners which may be considered as normal could be in fact suboptimal or abnormal for athletes and would reflect severe deficiency. It is well known from animal experiments that chronic iron deficiency could affect the performances by reducing the activity of iron-dependent enzymatic systems in skeletal-muscle mitochondria (DAvIEs et al., 1984). This hypothesis could be tested in man by analyzing the activity of iron-depending enzymes in biopsy specimens taken from skeletal muscles.

Iron deficiency in athletes is a common feature. The possible causes of this phenomenon have been reviewed by PaTE (1983). According to PATE (1983), the low iron storage in athletes who are in caloric balance could be a reduced iron absorption from the gut and high rate of iron loss through sweating and hemolysis. Iron loss through sweating cannot be evaluated on the basis of the present study but the low $\mathrm{Hp}$ levels in the runners clearly demonstrate that intravascular hemolysis occurs in these subjects. It has been hypothesized that high rate of hemolysis in runners is the result of mechanical destruction of fragile RBC in the capillaries of the feet caused by the impact of the footsoles on the ground (Duraux et al., 1981). As shown in Table I, the mean Hp concentration in the runners is lower than in control subjects who took part in the study of Dufaux et al. (1981). The lowest mean Hp values have been found in the long- and middle-distance runners. These mean $\mathrm{Hp}$ concentrations are below the normal value $(<40 \mathrm{mg} / 100 \mathrm{ml})$ but they do not differ significantly from the mean $\mathrm{Hp}$ concentration measured in the sprinters.

The results of the present investigation show that the iron status of runners differs significantly from control subjects. Despite the fact that mean $\mathrm{Hb}, \mathrm{Ht}, \mathrm{RBC}$, SI and SF concentrations are within the normal range many athletes manifest iron deficiency and anemia. Their tendency to suffer from iron deficit and anemia requires adequate treatment and systematic screening for iron deficiency and suboptimal $\mathrm{Hb}$ levels. As the hematological parameters measured in the present study do not significantly differ among the three groups of runners, it can be concluded that the iron status of these athletes does not depend on the peculiarities of their athletic speciality.

\section{References}

BlaCKLoK, N. S. (1977) Brit. J. Urol. 49, 127-132.

Brotherhood, J., Brozovie, B. \& Pugr, L. G. C. (1975) Clin. Sci. Molec. Med. 48, 139-145.

Celsing, F., Blomstrand, E., Werner, B., Plalstedt, P. \& Ekblom, B. (1986) Med. Sci. Sports Exerc. $18,156-161$.

Clement, D. B. \& Asmundson, R. C. (1982) Phys. Sports Med. 10, 37-43.

Davies, K. J. A., Donovan, C. M., Refino, C. A., Brooks, G. A., Packer, L. \& Dallman, P. R. (1984) Amer. J. Physiol. 246, E535-E543.

Dufaux, B., Hoederath, A., Streitberger, I., Hollmann, W. \& Assmann, G. (1981) Int. J. Spotts Med. 2, 43-46.

Ehn, L., Carlmark, B. \& Höglund, J. (1980) Med. Sci. Sports Exerc. 12, 61-64.

Ericsson, P. (1970) Acta Med. Scand. 188, 361-374.

Goldie, D. J. \& Thomas, M. J. (1978) Ann. Clin. Biochem. 15, 102.

Lipschitz, D. A., CoOK, J. D. \& Finch, C. A. (1974) New Engl. J. Med. 290, 1213-1216. 
Ohira, Y., Edgerton, V. R., Gardner, G. W., Stenewiratne, B., Barnard, R. J. \& Simpson, D. R. (1979) Brit. J. Haematol. 41, 365-372.

Pate, R. R. (1983) Phys. Sports Med. 11, 115-131.

Stookey, L. L. (1970) Anal. Chem. 42, 779.

\section{G. CAMUS}

Research Associate, F.N.R.S.

Laboratoire de Physiologie Humaine Appliquée,

I.S.E.P., Université de Liège,

B-4000 Liège 